\title{
Adoption of Transactional Service in Electronic Government - A case of Pak-Identity Service
}

\author{
Muhammad Mahboob Khurshid ${ }^{1(a, b)[0000-0002-0323-1088]^{*},}$ Nor Hidayati Zakaria², Ammar \\ Rashid $^{3}$, Yunis Ali Ahmed ${ }^{4}$, Muhammad Noman Shafique ${ }^{5}$ \\ ${ }^{1 a}$ Department of Examinations, Virtual University of Pakistan, Lahore, Pakistan \\ ${ }^{1 b}$ School of Computing, Faculty of Engineering, Universiti Teknologi Malaysia, Johor Bahru, \\ Malaysia \\ mehboob. khursheed@vu . edu . pk; mahboob. khursheed@gmail . com \\ ${ }^{2}$ Azman Hashim International Business School, Universiti Teknologi Malaysia, Kuala Lumpur, \\ Malaysia \\ hidayati@utm.my \\ ${ }^{3}$ College of IT, Ajman University, Ajman, UAE \\ a.rashideajman.ac.ae \\ ${ }^{4}$ Faculty of Computing, SIMAD University, Mogadishu, Somalia \\ yunisaliesimad.edu.so \\ ${ }^{5}$ Dongbei University of Finance and Economics, Dalian, China \\ shafique.nouman@gmail.com
}

\begin{abstract}
Governments around the world are using information and communication technologies to offer both simple information portals and transactional services. A less than one-third of the electronic government (e-government) initiatives focused on the provision of transactional services and understanding on studies related to the adoption of such services using domain-specific adoption theories/models are scarce. Therefore, the objective of this study is to understand the adoption of transactional service system, i.e. 'Pak-Identity' by employing a domain-specific model, i.e. Unified Model of Electronic Government Adoption (UMEGA). A UMEGA model with four new constructs is validated using data gathered from 441 citizens from all over Pakistan. A survey was conducted among citizens using simple random sampling technique. The collected data were analyzed employing variance-based structure equation modelling, i.e. partial least squares technique in SmartPLS 3.0 to test the formulated hypotheses. Findings indicate that (1) facilitating conditions is the predictor of effort expectancy, (2) performance expectancy, trust, and herd behaviour are the predictors of attitude, (3) price value, grievance redressal, and attitude are the predictors of behavioural intention to use e-government service. Surprisingly, effort expectancy, facilitating conditions, social influence, and perceived risk are found to be the nonsignificant predictors of adoption of e-government service. Interestingly, new constructs and new relationships are exposed, i.e. trust and herd behaviour on attitude, and price value and grievance redressal on behavioural intention. Moreover, a 55\% variance in effort expectancy, $65 \%$ variance in attitude, and $40 \%$ variance in behavioural intention to adopt egovernment has been found. Implications for the academics and managers are also outlined.
\end{abstract}


Keywords: Electronic Government (E-Government), Transactional Service, UMEGA, Behavioural Intention, Adoption, Factors.

\section{Introduction}

Governments around the world are using information and communication technologies (ICTs) in order to upsurge effectiveness and efficiency in their services. Moreover, governments are providing services to their citizens using ICTs. In this connection, the conceptualization of the provision of services by the government to the public using ICTs is referred to as e-government [1]. On the one hand, there are several substantial benefits of e-government, such as increasing transparency, delivery of services, public engagement in different government decisions, and corruption reduction. However, on the other hand, several barriers of human, technical and organizational nature (such as active inter- and intra-organizational communication, monetary constraints, strong political will and support, awareness issues, security, and privacy concerns, and skills and abilities, hinder the implementation of e-government successfully [2].

Significant efforts are being undertaken by the countries (about 98\%) around the world to develop e-government portals which provide simple information; however, less than one-third of these efforts are related to the provision of transactional services [3]. Besides, the ratio of successfully completed e-government projects is only $15 \%$ $[4,5]$. One of the arduous issues in e-government transactional services is its adoption and diffusion [2]. Scholars are increasingly focusing on understanding the factors of adoption of e-government transactional service systems in primary and secondary stakeholders, particularly in developing countries [1] since such services are successful in developed countries [5]. Therefore, this research aims to investigate the factors affecting the citizens' adoption of e-government transactional services in Pakistan. Policy-makers in the government need to understand the adoption factors and instrumentalize related policies. This study can bring new insights for policy-makers to understand and increase the citizen's adoption of e-government from a transactional service perspective.

\section{Overview of E-Government Transactional Service - The 'Pak-Identity'}

The 'Pak-Identity' is one of the e-government transactional service system developed and launched by National Database and Registration Authority (NADRA), Pakistan through which online application facilities are provided to the Pakistani citizens for obtaining identity documents. It is a one-stop e-government service through which ten different identity documents can be applied online by the public such as identity card for local citizens (CNIC), National Identity Card of Overseas Pakistanis (NICOP), Pakistan Origin Card (POC), Family and Child Registration Certificates. These identity documents are then delivered to the citizens by mail. 


\section{Theoretical Foundations}

This study focuses on evaluating e-government adoption from a transactional service perspective (i.e. Pak-Identity system) using Unified Model of Electronic Government Adoption (UMEGA) developed by Dwivedi, Rana, Janssen, Lal, Williams and Clement [1]. The decision to choose UMEGA lies on the facts that (1) it is purely developed in electronic-government context, (2) it explains between $77 \%$ variance in EE, $49 \%$ variance ATT, and $80 \%$ variance in the behavioural intention to egovernment systems usability, (3) the model is developed after extensive study on previously nine competing models on assessing individuals' adoption of technology, (4) studies have reported UMEGA to be the superior performing model in egovernment studies and to measure adoption [6].

The UMEGA model is extended by adding four additional factors relevant to the context that may give a better understanding of the influencing factors on the adoption of e-government. To the best of our knowledge, no study was carried out so far that has empirically investigated the factors of adoption of e-government by employing UMEGA and examining additional factors, i.e. trust, herd behaviour, price value, and grievance redressal factors and hence, make a novel contribution to the adoption studies. Moreover, two new relationships are proposed, empirically investigated, and proved, i.e. the influence of trust and herd behaviour on attitude.

\section{Literature Review/Hypotheses Development}

\subsection{Performance Expectancy (PE)}

Previous studies reveal that PE is the most influential determinant to measure the innate probabilities of individuals in involving or adopting a new information system/ technology (IS/IT) [7, 8]. It has been accredited that improved job performance is a critical inducement for adopting IT/IS [5]. Moreover, the influence of PE on behavioural intention has been failed in a study conducted by Krishnaraju, Mathew and Sugumaran [9]. Therefore, successes and failures of PE construct have suggested the reconceptualization of PE and hence investigated its influence on adoption through attitude by Dwivedi, Rana, Janssen, Lal, Williams and Clement [1]. Based on these facts, we hypothesize that:

H1: There is a positive and significant relationship between PE and ATT toward using Pak-Identity.

\subsection{Effort Expectancy (EE)}

Actual and potential users would be willing to adopt an IS/IT if it is believed to be simple and easy to use despite its usefulness in their jobs [1]. Therefore, users will be intended to use a system if it is simple and effortless such that they need not make any hard efforts in using it. However, no support was found to have an influence of EE on the adoption of e-government in a study conducted by Lallmahomed, Lallmahomed 
and Lallmahomed [10]. In contrast, effort expectancy has been proposed to influence attitude in UMEGA [1]. Align with the UMEGA model, the hypothesis is proposed as:

H2: There is a positive and significant relationship between EE and ATT toward using Pak-Identity.

\subsection{Social Influence (SI)}

People live in a social system. They influence or motivate each other/one another to use an IS/IT. Social influence construct is regarded as one's self-instructed beliefs of others about system usage. It is a construct used to measure the users' beliefs of an IS/IT about what other people (like peers, friends, and family members) would be thinking as much important to use that IS/IT. Social influence is the most influential factor affecting individuals' attitudes to accept and use e-government systems [1, 6] and hence, is hypothesized as:

H3: There is a positive and significant relationship between SI and ATT toward using Pak-Identity.

\subsection{Facilitating Conditions (FC)}

An individual does not seem to have adequate technical and organizational facilities to use an IS/IT and hence will not be able and intend to use it. Thus, the higher the availability of technical resources and knowledge, the higher its adoption of egovernment systems and services. Align with these studies; we also conceptualize that FC has a positive and significant effect on adoption of e-government system [5, 6, 10]. Moreover, the influence of this factor on EE has also been conceptualized, hypothesized, and validated in previous studies $[1,6]$. Thus, the following two hypotheses have been framed:

H4: There is a positive and significant relationship between FC and BI toward using Pak-Identity.

H5: There is a positive and significant relationship between FC and EE toward using Pak-Identity.

\subsection{Perceived Risk (PR)}

Individuals may not use or limit their interactions with a government system because of the risks or losses associated with it. Perceived risks are the security concerns or anxieties, such as revealing their identities and making transactions online in using egovernment systems. These and such other types of anxieties or uncertainties will restrict them to adopt e-government systems. Perceived risk is found to be the significant negative predictor that influences attitudes towards using e-government technologies. Thus, we hypothesize that:

H6: There is a negative and significant relationship between PR and ATT toward using Pak-Identity. 


\subsection{Trust (TRST)}

Trust is a complex and multilayered concept spanning across varied disciplines; thus; it is defined according to the context and discipline. However, generally, trust is taken as a trust in internet technologies $[10,11]$. Trust is considered an e-government service to be trustworthy, secure, reliable, and accurate. Trust has also been found to be the significant positive predictor of adoption of e-government $[6,12,13]$. However, this construct has also been found to be a significant predictor of attitude at pre-usage [14] and post-usage stages $[14,15]$. We hypothesize trust as the significant positive predictor of building citizens' attitudes towards e-government adoption:

H7: There is a positive and significant relationship between TRST and ATT toward using Pak-Identity.

\subsection{Herd Behaviour $(\mathrm{HB})$}

Herd behaviour is conceptualized as an individual's followings in adopting an IS/IT even when his or her private information suggests doing the opposite [16]. HB is a self-observation about the behaviour of other people in adopting an IS/IT and does not depend on what others think [17]. Thus, the more the users are observatory about the practices of others in adopting technology, the more they adopt it. Therefore, we hypothesize $\mathrm{HB}$ as an indirect predictor of behavioural intention towards using egovernment service, i.e. Pak-Identity, through attitude:

H8: There is a positive and significant relationship between HB and ATT toward using Pak-Identity.

\subsection{Price Value $(\mathrm{PV})$}

An individual will be inclined to use e-government system or service if its benefits are higher as compared to its monetary cost [7]. This construct is considered for having a significant role in the studies related to technology adoption as well as e-government studies [10]. Based on the evidence from previous literature on e-government, it is hypothesized that:

H9: There is a positive and significant relationship between PV and BI toward using Pak-Identity.

\subsection{Grievance Redressal (GR)}

Grievance redressal is defined as a mechanism/system to address the disputes between a consumer and a service provider. Since there may arise some legal disputes between the government and the citizens while making transactions by the public and resolution of such disputes is necessary, provision of grievance redressal is quite necessary. Grievance redressal has been very effective in developing countries like India, that have contributed to creating positive impacts on individuals' use of services $[18,19]$. Previous research has evidenced that grievance redressal bears a significant positive 
predictor of m-wallets use intentions [20]. Thus, in this study, grievance redressal has been hypothesized as:

H10: There is a positive and significant relationship between GR and BI toward using Pak-Identity.

\subsection{Attitude (ATT)}

Attitude is described as the degree to which a unit of adoption has a positive evaluation of the behaviour in question. Most recent studies, including [1, 21] have postulated the role of attitude in measuring adoption of IS/IT. Moreover, the attitude has also been investigated to influence behavioural intention to use e-government [6]. Thus, we hypothesize attitude as:

H11: There is a positive and significant relationship between ATT and BI toward using Pak-Identity.

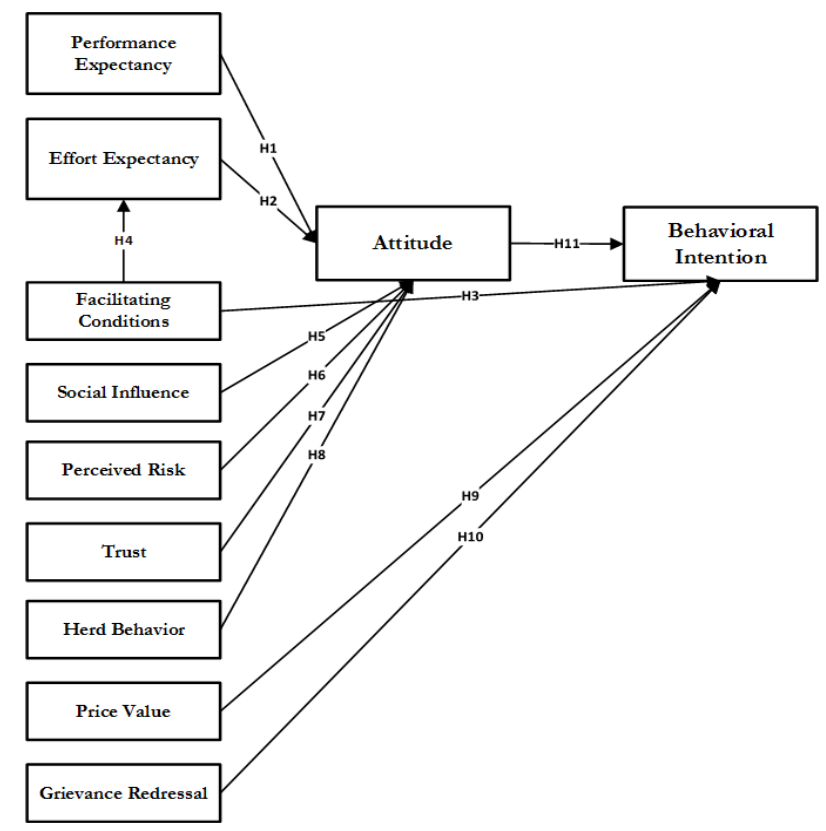

Fig. 1. Proposed Research Model

\section{$5 \quad$ Methods}

We employed partial least squares - structure equation modeling (PLS-SEM) technique using SmartPLS 3.0 to analyze the collected data and test the hypotheses. Moreover, a simple random sampling technique was adopted to collect data from citizens [22]. A questionnaire was designed by adapting scales from previous studies to examine the research question. The items of the constructs were based on previous 
studies in which they had already been used and tested. These studies included [1, 6 , $12,20,23]$. A survey was undertaken among citizens to seek substantial insights after investigating the influencing factors on the adoption of e-government service, i.e. Pak-Identity facilitated by NADRA. A self-administered online questionnaire was set up to collect data. A total number of 441 respondents participated in this survey, whereas the data collection took place three months long. The questionnaire was divided into two parts, including demographic questions and questions about all the constructs. Each construct consisted of a minimum of three items and respondents were asked to provide their opinions in one of the predefined choices like 'Extremely Disagree', 'Disagree', 'Neutral', 'Agree', and 'Extremely Agree'. A small introduction about e-government transactional service, i.e. Pak-Identity, was presented before the respondents to give them an introduction about the service understudied.

The questionnaire also comprised of ordinal questions concerning the age group, education, occupation, and age of the respondents. No extrinsic incentive or reward scheme was introduced to the respondents to increase their participation in this survey except a voluntary will. Since a significant percentage (i.e. 75\%) of the respondents was well-educated, participated in the survey, we are sure about citizens' high degree of competencies to answer the questions. Therefore, we are confident that the respondents are suitable for the study.

\section{$6 \quad$ Findings}

Of the study population, 143 are females, and 298 are males. A total number of 112 participants are of having 12-year of schooling, 176 are of having 14-year of schooling, 123 are postgraduates, and qualification level of 29 participants is postgraduate research. A total number of 188 are students who participated in this research survey, 28 are unemployed, 28 are self-employed, 121 are employees of private-sector, and 76 are employees of public-sector. A total number of 206 participants are 18-24 years old, 104 are 25-29 years old, 67 are 30-34 years old, 40 are 35-39 years old, 15 are 40-44 years old, 2 are 45-49 years old, 4 are 50-54 years old, 3 are 55-59 years old and no participant is above 59 years of age.

\subsection{Measurement Model}

We have assessed the measurement model by applying reliabilities and validities tests such as Cronbach's Alpha, composite reliability, convergent validity, average variance extracted (AVE), and discriminant validity. Following the recommendations of Hair, Hult, Ringle and Sarstedt [24], the threshold values of Cronbach's Alpha ( $\boldsymbol{\alpha}$ ), composite reliability, and indicator's reliability have been set to greater than 0.7 whereas the threshold value of AVE has been set to greater than 0.5. All the values are above the threshold values and demonstrated in Table 1.

Table 1. Reliability and Validity Statistics

\begin{tabular}{lllll}
\hline Constructs & Items & Cronbach's $\alpha$ & Composite & AVE \\
\hline
\end{tabular}




\begin{tabular}{lllcl}
\hline & & \multicolumn{3}{c}{ Reliability } \\
\hline Performance Expectancy (PE) & 3 & 0.918 & 0.948 & 0.859 \\
Effort Expectancy (EE) & 3 & 0.899 & 0.937 & 0.833 \\
Social Influence (SI) & 3 & 0.857 & 0.912 & 0.776 \\
Facilitating Conditions (FC) & 3 & 0.859 & 0.914 & 0.780 \\
Perceived Risk (PR) & 3 & 0.919 & 0.944 & 0.849 \\
Trust (TRST) & 3 & 0.939 & 0.961 & 0.891 \\
Herd Behaviour & 3 & 0.829 & 0.897 & 0.745 \\
Price Value (PV) & 3 & 0.885 & 0.928 & 0.810 \\
Grievance Redressal (GR) & 3 & 0.923 & 0.951 & 0.867 \\
Attitude (ATT) & 3 & 0.958 & 0.973 & 0.923 \\
Behavioural Intention (BI) & 3 & 0.903 & 0.939 & 0.837 \\
\hline
\end{tabular}

Finally, we check for the construct's discriminant validity [24]. Table 2 presents the results of the evaluation for discriminant validity test. We have detected no anomalies using this test (see Table 2). Overall, our constructs show excellent measurement properties in terms of reliabilities and validities.

Table 2. Fornell-Larcker Criterion

\begin{tabular}{|c|c|c|c|c|c|c|c|c|c|c|c|}
\hline & PE & SI & $\mathrm{FC}$ & ATT & BI & HB & $\mathrm{EE}$ & GR & PR & PV & $\begin{array}{l}\text { TRS } \\
\mathrm{T}\end{array}$ \\
\hline PE & $\begin{array}{r}0 . \\
927\end{array}$ & & & & & & & & & & \\
\hline SI & $\begin{array}{r}0 . \\
677\end{array}$ & $\begin{array}{r}0 . \\
881\end{array}$ & & & & & & & & & \\
\hline FC & $\begin{array}{r}0 . \\
667\end{array}$ & $\begin{array}{r}0 . \\
739\end{array}$ & $\begin{array}{r}0 . \\
883\end{array}$ & & & & & & & & \\
\hline $\mathrm{AT}$ & $\begin{array}{r}0 . \\
670\end{array}$ & $\begin{array}{r}0 . \\
640\end{array}$ & $\begin{array}{r}0 . \\
631\end{array}$ & $\begin{array}{r}0 . \\
961\end{array}$ & & & & & & & \\
\hline BI & $\begin{array}{r}0 . \\
667\end{array}$ & $\begin{array}{r}0 . \\
507\end{array}$ & $\begin{array}{r}0 . \\
470\end{array}$ & $\begin{array}{r}0 . \\
569\end{array}$ & $\begin{array}{r}0 . \\
915\end{array}$ & & & & & & \\
\hline HB & $\begin{array}{r}0 . \\
594\end{array}$ & $\begin{array}{r}0 . \\
558\end{array}$ & $\begin{array}{r}0 . \\
622\end{array}$ & $\begin{array}{r}0 . \\
691\end{array}$ & $\begin{array}{r}0 . \\
494\end{array}$ & $\begin{array}{r}0 . \\
863\end{array}$ & & & & & \\
\hline $\mathrm{EE}$ & $\begin{array}{r}0 . \\
769\end{array}$ & $\begin{array}{r}0 . \\
738\end{array}$ & $\begin{array}{r}0 . \\
742\end{array}$ & $\begin{array}{r}0 . \\
652\end{array}$ & $\begin{array}{r}0 . \\
565\end{array}$ & $\begin{array}{r}0 . \\
619\end{array}$ & $\begin{array}{r}0 . \\
912\end{array}$ & & & & \\
\hline GR & $\begin{array}{r}0 . \\
621\end{array}$ & $\begin{array}{r}0 . \\
461\end{array}$ & $\begin{array}{r}0 . \\
468\end{array}$ & $\begin{array}{r}0 . \\
496\end{array}$ & $\begin{array}{r}0 . \\
508\end{array}$ & $\begin{array}{r}0 . \\
432\end{array}$ & $\begin{array}{r}0 . \\
531\end{array}$ & $\begin{array}{r}0 . \\
931\end{array}$ & & & \\
\hline PR & $\begin{array}{r}0 . \\
101\end{array}$ & $\begin{array}{r}0 . \\
169\end{array}$ & $\begin{array}{r}0 . \\
196\end{array}$ & $\begin{array}{r}0 . \\
105\end{array}$ & $\begin{array}{r}0 . \\
053\end{array}$ & $\begin{array}{r}0 . \\
239\end{array}$ & $\begin{array}{r}0 . \\
152\end{array}$ & $\begin{array}{r}0 . \\
083\end{array}$ & $\begin{array}{r}0 . \\
922\end{array}$ & & \\
\hline PV & $\begin{array}{r}0 . \\
563\end{array}$ & $\begin{array}{r}0 . \\
622\end{array}$ & $\begin{array}{r}0 . \\
646\end{array}$ & $\begin{array}{r}0 . \\
565\end{array}$ & $\begin{array}{r}0 . \\
408\end{array}$ & $\begin{array}{r}0 . \\
552\end{array}$ & $\begin{array}{r}0 . \\
602\end{array}$ & $\begin{array}{r}0 . \\
288\end{array}$ & $\begin{array}{r}0 . \\
206\end{array}$ & $\begin{array}{r}0 . \\
900\end{array}$ & \\
\hline $\begin{array}{l}\text { TRS } \\
\mathrm{T}\end{array}$ & $\begin{array}{r}0 . \\
656\end{array}$ & $\begin{array}{r}0 . \\
644\end{array}$ & $\begin{array}{r}0 . \\
629 \\
\end{array}$ & $\begin{array}{r}0 . \\
703\end{array}$ & $\begin{array}{r}0 . \\
531\end{array}$ & $\begin{array}{r}0 . \\
631 \\
\end{array}$ & $\begin{array}{r}0 . \\
589\end{array}$ & $\begin{array}{r}0 . \\
457\end{array}$ & $\begin{array}{r}0 . \\
080\end{array}$ & $\begin{array}{r}0 . \\
592 \\
\end{array}$ & $\begin{array}{r}0 . \\
944 \\
\end{array}$ \\
\hline
\end{tabular}




\subsection{Structural Model}

In the structural model, the coefficient of determination $\left(\mathrm{R}^{2}\right)$ and the significant values ( $\mathrm{p}$ values) are assessed. The $\mathrm{R}^{2}$ value of EE is 0.551 , ATT is 0.647 , and $\mathrm{R}^{2}$ value of BI is 0.404 (see Table 4). It is found that there is a high explanatory variance of EE, ATT, and BI. The p-values (less than 0.05 ) of the hypothesized relationships are considered as significant values and lead to the acceptance of a hypothesis (Table 3 ).

Table 3. Testing of Hypotheses

\begin{tabular}{lcccl}
\hline Path & $\beta$ & T Statistics & p-values & Remarks \\
\hline$H 1: P E \rightarrow A T T$ & 0.151 & 2.185 & 0.029 & Supported \\
$H 2: E E \rightarrow A T T$ & 0.098 & 1.304 & 0.193 & Not-Supported \\
$H 3: F C \rightarrow B I$ & 0.065 & 0.956 & 0.339 & Not-Supported \\
$H 4: F C \rightarrow E E$ & 0.742 & 17.592 & 0.000 & Supported \\
$H 5: S I \rightarrow A T T$ & 0.122 & 1.834 & 0.067 & Not-Supported \\
$H 6: P R \rightarrow A T T$ & -0.041 & 1.387 & 0.166 & Not-Supported \\
H7: $T R S T \rightarrow A T T$ & 0.276 & 4.354 & 0.000 & Supported \\
$H 8: H B \rightarrow A T T$ & 0.308 & 5.503 & 0.000 & Supported \\
H9: $P V \rightarrow B I$ & 0.095 & 1.974 & 0.049 & Supported \\
$H 10: G R \rightarrow B I$ & 0.285 & 4.060 & 0.000 & Supported \\
$H 11: A T T \rightarrow B I$ & 0.333 & 4.995 & 0.000 & Supported \\
\hline$p<0.05$ & & & &
\end{tabular}

Table 4. Coefficient of Determination $\left(\mathrm{R}^{2}\right)$

\begin{tabular}{lccc}
\hline Endogenous Variables & $\mathrm{R}^{2}$ & T Statistics & $\mathrm{p}$-values \\
\hline Attitude & 0.647 & 13.063 & 0.000 \\
Behavioural Intention & 0.404 & 5.780 & 0.000 \\
Effort Expectancy & 0.551 & 8.912 & 0.000 \\
\hline
\end{tabular}

This study has found seven out of eleven hypotheses supported since the p-values are less than 0.05 . The most striking results attained from the analysis are that $\mathrm{PE}$ does have an influence on ATT, FC on EE, GR on BI, TRST on ATT, HB on ATT, $\mathrm{PV}$ on BI, and ATT does influence behavioural intention to use e-government service. The results that PE influences on ATT, FC on EE, TRST on ATT, HB on ATT, PV on BI, GR on BI, and ATT influences on BI are aligned with the previous studies [1, 6, $12,20,23]$. Moreover, the influence of EE on BI is not supported in this study which is aligned the earlier studies $[6,10]$ whereas it contradicts with the assumption of the base theory, i.e. UMEGA [1]. On the other hand, the influence of SI on ATT is supported in one study [6] whereas it is not supported in another study [10]. Surprisingly, although PR is negatively influencing, it is not supported in this study, whereas it has been proved to have a significant negative influence on ATT $[1,6]$. The results are 
more attractive such that $55 \%$ of variance has been explained in effort expectancy and $64.7 \%$ of variance has been explained in attitude whereas $40.4 \%$ of the variance is explained in behavioural intention to use e-government.

\section{$7 \quad$ Discussion and Implications}

This research is conducted, including the citizens of all domains. It can be deduced from the research that a UMEGA model, which has been extended according to the context, can be used to identify directions for policy-makers to increase the citizens' intentions to use e-government transactional services which are then lead to its wide use. Identification of these insights and, in return, improvement in e-government policies will lead to achieving high-level benefits such as transparency, access to information, efficient delivery of services, and citizens' engagement.

Being $\mathrm{H} 1$ to be accepted postulates that the relationship between performance expectancy and attitude is strong. Thus, users' perceptions of performance would play a vital role in constructing positive attitudes, which will then lead to high intention in using e-government services. Policy-makers should take actions in making egovernment services user-friendly and beneficial in citizens' daily lives, such as applying online and obtaining identity documents at home without making long journeys.

H4 is also accepted, which evidences that the availability of technical and organizational infrastructure would affect the users' attitudes positively through minimizing the efforts in using e-government services. Accordingly, policy-makers should make policies to arrange for training and support to users at the organizational level, internet facilities, and unique customer access outlets [1]. Moreover, they should invest more in developing public-private partnerships and hire analysts/designers so that easy to use and easily understandable applications can be developed in applying for identity documents.

Users perceptions about trust in e-government services are also contributing towards building attitudes, which would then lead to upsurge the intentions to use services since $\mathrm{H} 7$ is accepted. The e-government services should be reliable, secure, and trustworthy, which would shape the users' attitudes in using them. Therefore, the responsible authorities should concentrate on shaping users' beliefs by ensuring citizens' security and privacy concerns. Multiple authentications while making payment transactions for obtaining identity documents can be implemented for this purpose [10].

The empirical analysis in this study also supports hypothesis H8. Accordingly, herd behaviour, which is the user's self-observations about using technology or service by other people, is the predictor in forming attitudes. Users will articulate their attitudes if they are observing Pak-Identity a dominant service in the society since a large number of people will be using it. Therefore, policy-makers should make such policies through which use of e-government service should be largely discernable to the society (e.g. elevating awareness campaigns) [1]. 
Pak-Identity service requires the internet, computers, and other equipment for the printing, uploading, and downloading scanned documents (e.g. forms, photographs). Users would be inclined to use e-government transactional services if it is a good substitute for perceived benefits over incurred costs. Hypothesis H9 is accepted, which postulates that price value is a significant positive predictor of behavioural intention. Thus, policy-makers should make policies which help in delivering inexpensive technological services or the service that requires less equipment to the maximum extent.

A novelty in this research is the introduction of grievance redressal to investigate its influence on behavioural intention to use e-government transactional service i.e. Pak-Identity. This study reveals the hypothesis H10 'supported' by the empirical analysis. Legal disputes between the service providers and users should be resolved timely and transparently (e.g. payment clearance for applying identity documents). Moreover, safe and secure service would form users' behavioural intention to use it [20]. For this purpose, a continuous monitoring system/mechanism should be observed by top officials.

Hypothesis $\mathrm{H} 11$ postulates a strong positive linkage between attitude and behavioural intention to use e-government transactional service i.e. Pak-Identity. Thus, policy-makers should instrumentalize in increasing attitudes (by demonstrating benefits to the users), which will lead to increasing intentions.

\section{Conclusion, Limitations, and Future Directions}

To sum up, our work has investigated the predictors of adoption of e-government by employing UMEGA model since studies on the adoption of transactional services in e-government by applying domain-specific theories/models are scarce. The evidence from this study intimate that adoption of e-government is influenced by some factors determined by impacts on citizens' attitude and behavioural intention. The findings prove that performance expectancy, trust, and herd behaviour are influencing factors of attitude, facilitating conditions of effort expectancy whereas grievance redressal, price value, and attitude are influencing factors of behavioural intention to use egovernment transactional service, i.e. Pak-Identity. The model has explained $55 \%$ of the variance in effort expectancy, $65 \%$ of the variance in attitude, and $40 \%$ of the variance in behaviour intention to use e-government by the citizens. Our study provides suitable bases for a new way to conduct adoption studies on e-government using UMEGA [1]. These findings add to a vast growing body of knowledge on egovernment adoption, which has particular implications for the academics and managers.

Limitation of the survey id that respondents/citizens are limited to e-government users in Pakistan only and care should be exercised when generalizing these results to other countries. Moreover, future researchers are invited to conduct studies on other e-government transactional services where difference/comparison of factors in adopting various e-government transactional services can make more significant insights for the policy-makers. Since the model underperformed concerning the explained 
variance of behavioural intention as compared to UMEGA, future researchers should investigate some other factors which can accelerate the citizens' behavioural intention to use e-government.

\section{References}

1. Dwivedi, Y.K., Rana, N.P., Janssen, M., Lal, B., Williams, M.D., Clement, M.: An empirical validation of a unified model of electronic government adoption (UMEGA). Government Information Quarterly 34, 211-230 (2017)

2. Palvia, S., Anand, A.B., Seetharaman, P., Verma, S.: Imperatives and Challenges in using EGovernment to Combat Corruption: A Systematic Review of Literature and a Holistic Model. Americas Conference on Information Systems. Association for Information Systems, Boston, USA (2017)

3. Taheri, F., Mirghiasi, S.R.: Presenting a Typology of Users Satisfaction Model from Electronic Government. International Academic Journal of Organizational Behavior and Human Resource Management 3, 11-26 (2016)

4. Heeks, R., Bailur, S.: Analyzing e-government research: Perspectives, philosophies, theories, methods, and practice. Government Information Quarterly 24, 243-265 (2007)

5. Ali, U., Mehmood, A., Majeed, M.F., Muhammad, S., Khan, M.K., Song, H., Malik, K.M.: Innovative Citizen's Services through Public Cloud in Pakistan: User's Privacy Concerns and Impacts on Adoption. Mobile Networks and Applications 24, 47-68 (2019)

6. Verkijika, S.F., De Wet, L.: E-government adoption in sub-Saharan Africa. Electronic Commerce Research and Applications 30, 83-93 (2018)

7. Venkatesh, V., Thong, J.Y.L., Xu, X.: Consumer Acceptance and Use of Information Technology: Extending the Unified Theory of Acceptance and Use of Technology. MIS Quarterly 36, 157-178 (2012)

8. Venkatesh, V., Morris, M.G., Davis, G.B., Davis, F.D.: User Acceptance of Information Technology: Toward a Unified View. MIS Quarterly 27, 425-478 (2003)

9. Krishnaraju, V., Mathew, S.K., Sugumaran, V.: Web personalization for user acceptance of technology: An empirical investigation of E-government services. Information Systems Frontiers 18, 579-595 (2016)

10.Lallmahomed, M.Z., Lallmahomed, N., Lallmahomed, G.M.: Factors influencing the adoption of e-Government services in Mauritius. Telematics and Informatics 34, 57-72 (2017)

11.Abu-Shanab, E.A.: E-government familiarity influence on Jordanians' perceptions. Telematics and Informatics 34, 103-113 (2017)

12.Alzahrani, L., Al-Karaghouli, W., Weerakkody, V.: Investigating the impact of citizens' trust toward the successful adoption of e-government: A multigroup analysis of gender, age, and internet experience. Information Systems Management 35, 124-146 (2018)

13.Rehman, M., Kamal, M.M., Esichaikul, V.: Adoption of e-Government Services in Pakistan: A Comparative Study Between Online and Offline Users. Information Systems Management 33, 248-267 (2016)

14.Venkatesh, V., Thong, J.Y.L., Chan, F.K.Y., Hu, P.J.-H., Brown, S.A.: Extending the twostage information systems continuance model: incorporating UTAUT predictors and the role of context. Information Systems Journal 21, 527-555 (2011) 
15.Zuiderwijk, A., Cligge, M.: The Acceptance and Use of Open Data infrastructures-Drawing upon UTAUT and ECT. In: Electronic Government and Electronic Participation: Joint Proceedings of Ongoing Research, PhD Papers, Posters and Workshops of IFIP EGOV and EPart 2016, pp. 91. IOS Press, (Year)

16.Banerjee, A.V.: A Simple Model of Herd Behavior. The Quarterly Journal of Economics 107, 797-817 (1992)

17.Sun, H.: A longitudinal study of herd behavior in the adoption and continued use of technology. MIS Quarterly 37, (2013)

18.Rana, N.P., Dwivedi, Y.K., Williams, M.D., Weerakkody, V.: Adoption of online public grievance redressal system in India: Toward developing a unified view. Computers in Human Behavior 59, 265-282 (2016)

19.Rana, N.P., Dwivedi, Y.K., Williams, M.D., Lal, B.: Examining the Success of the Online Public Grievance Redressal Systems: An Extension of the IS Success Model. Information Systems Management 32, 39-59 (2015)

20.Kumar, A., Adlakaha, A., Mukherjee, K.: The effect of perceived security and grievance redressal on continuance intention to use $\mathrm{M}$-wallets in a developing country. International Journal of Bank Marketing 36, 1170-1189 (2018)

21.Dwivedi, Y.K., Rana, N.P., Jeyaraj, A., Clement, M., Williams, M.D.: Re-examining the Unified Theory of Acceptance and Use of Technology (UTAUT): Towards a Revised Theoretical Model. Information Systems Frontiers (2017)

22.Zikmund, W.G., Babin, B.J., Carr, J.C., Griffin, M.: Business Research Methods. Cengage Learning (2013)

23.Vinnik, V.: User adoption of mobile applications: Extension of UTAUT2 model. vol. Master of Science in Economics and Business Administration. Norwegian School of Economics (2017) 24.Hair, J.F., Hult, G.T.M., Ringle, C.M., Sarstedt, M.: A Primer on Partial Least Squares Structural Equation Modeling (PLS-SEM). SAGE Publications, Inc; (2017) 